\title{
Dissociation Kinetics of the Streptavidin-Biotin Interaction Measured Using Direct Electrospray Ionization Mass Spectrometry Analysis
}

\author{
Lu Deng, Elena N. Kitova, John S. Klassen
}

Department of Chemistry and Alberta Glycomics Centre, University of Alberta, Edmonton, Alberta T6G 2G2, Canada

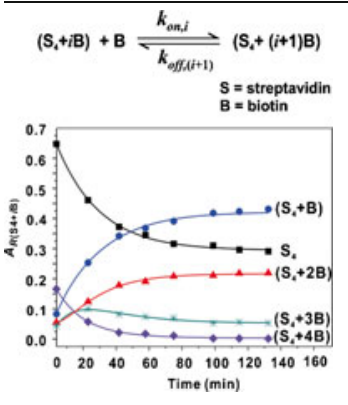

measured using a radiolabeled biotin assay. Importantly the dissociation activation energies determined by ESI-MS agree, within $1 \mathrm{kcalmol}^{-1}$, with the reported value. In addition to providing a quantitative measure of $k_{\text {off }}$, the results of the ESI-MS measurements revealed that the apparent cooperative distribution of $\left(\mathrm{S}_{4}+i \mathrm{~B}\right)$ species observed at short reaction times is of kinetic origin and that sequential binding of $\mathrm{B}$ to $\mathrm{S}_{4}$ occurs in a noncooperative fashion with the four ligand binding sites being kinetically and thermodynamically equivalent and independent.

Key words: Electrospray ionization mass spectrometry, Rate constants, Protein-ligand complexes

\section{Introduction}

$\mathrm{N}$ oncovalent interactions between proteins and between proteins with other biopolymers, small molecules, or metal ions are critical to most cellular processes. The abundances of protein complexes and their lifetimes reflect the rates of the corresponding association and dissociation reactions. Quantification of the kinetic parameters - the association and dissociation rate constants $\left(k_{\text {on }}\right.$ and $k_{\text {off }}$, respectively) - under specific solution conditions (e.g., $\mathrm{pH}$, temperature, ionic strength) is important in understanding the structure and function of protein complexes and is relevant to drug design [1-3]. There exist a number of established experimental techniques for measuring the rates of biochemical reactions, including association and dissociation reactions. These include surface plasmon resonance [4, 5], spectroscopic methods (e.g., atomic force spectroscopy, circular dichroism, or fluorescence-based approaches) [6-

Electronic supplementary material The online version of this article (doi:10.1007/s13361-012-0533-5) contains supplementary material, which is available to authorized users.

Correspondence to: John S. Klassen; e-mail: john.klassen@ualberta.ca
10], kinetic capillary electrophoresis [11, 12], radiolabeling combined with filtration/dialysis [13, 14] and NMR [15]. Many of these techniques require the labeling of one of the binding partners, their attachment to a surface or some other manipulation of the system, which can complicate the interpretation of the kinetic data and, in some instances, influence the rates of the reactions being investigated [16].

Electrospray ionization mass spectrometry (ESI-MS) has emerged as an important addition to the arsenal of techniques available for measuring the kinetics of chemical and biochemical reactions [17-28]. The ESI-MS approach is attractive as there is no requirement for labeling or immobilization since the identity of reactants and products and, possibly intermediates, can usually be established directly from the measured mass-to-charge ratios $(\mathrm{m} / \mathrm{z})[18$, 29]. Moreover, ESI-MS analysis allows for multiple reactions to be monitored simultaneously, a feature not associated with most kinetic assays. The determination of reaction rates by ESI-MS analysis normally follows one of two general strategies: on-line (real-time) monitoring of the reaction mixture, and off-line analysis, usually following a quench step that stops the reaction. The advantage of the online approach is that it allows, in principle, for direct analysis of 
the time-dependent distribution of reactants, intermediates, and products. The minimum acquisition time for an ESI mass spectrum, which is typically in the s to min range (although it varies between instruments and the nature of the sample being analyzed), places restrictions on the speed of reactions that can be reliably analyzed using the on-line approach. For this reason, real-time ESI-MS kinetic measurements are most commonly applied to relatively slow reactions, with timescales $>$ min. However, there are examples where ESI-MS has been successfully applied to relatively fast reactions, in the ms to s range $[17,18,20,22,24,25]$. The measurement of fast kinetics typically requires the use of rapid mixing systems, such as a continuous-flow [17, 18, 20, 22], rapid quenchedflow apparatus [24], or stopped-flow [25, 26]. The off-line approach is generally easier to implement and affords greater flexibility in terms of the experimental conditions under which the reactions are carried out. For example, this approach is suitable for the analysis of enzyme kinetics under solution conditions that are not amenable to direct ESI-MS analysis, such as high concentrations of salts or non-volatile buffers (e.g., PBS, citrate, HEPES, or TRIS) that are commonly used to stabilize proteins and ensure relevance to physiological conditions. Following the quench step, the solvent composition can be altered in order to facilitate detection of reactants or products by ESI-MS. However, a limitation of the off-line approach is that information on the distribution of species present under the reaction conditions of interest may be lost.

ESI-MS has been used to study the reaction rates for a variety of non-covalent protein interactions, including protein-protein [19, 20, 30], protein-small molecule [31] and protein-metal ion complexes [32], as well as for other biological complexes, such as DNA duplexes [33, 34]. However, to the best of our knowledge, absolute values of $k_{\text {on }}$ and $k_{\text {off }}$ for protein-ligand interactions measured using this approach have not been previously reported. Here, we describe the application ESI-MS for quantifying $k_{\text {off }}$ for the high affinity interaction between biotin (B) and a truncated form (containing residues 13-139) of wild-type (WT) streptavidin. Streptavidin is a homotetrameric protein complex $\left(\mathrm{S}_{4}\right)$ that is isolated from Streptomyces avidinii [35]. Each streptavidin subunit is organized into an eight-stranded $\beta$-barrel, with a binding site for $\mathrm{B}$ at one end [36]. The streptavidin-biotin interaction is one of the most stable in nature and the exceptionally high affinity $\left(K_{a}\right.$ of $\sim 2.5 \times$ $10^{13} \mathrm{M}^{-1}$ at $\mathrm{pH} 7.4$ and $25^{\circ} \mathrm{C}$ ) arises from an unusually small dissociation rate constant $\left(5.4 \times 10^{-6} \mathrm{~s}^{-1}\right.$ at $\mathrm{pH} 7.4$ and $25^{\circ} \mathrm{C}$ ) [13]. The origin of the slow dissociation kinetics has been the focus of many experimental and theoretical studies $[13,14,37-40]$. For example, the temperature dependence of $k_{\text {off }}$ for the interaction between B and WT streptavidin has been compared with values measured for a variety of single site mutants in an effort to elucidate the influence of the specific amino acid side chains on the kinetic barrier to dissociation $[13,14,41]$. These data were measured using a radiolabeled $\mathrm{B}$ assay, whereby the release of bound $\mathrm{B}$ from $\left(\mathrm{S}_{4}+4 \mathrm{~B}\right)$ complex was monitored in the presence of an excess of unlabeled B. In the present study, values of $k_{\text {off }}$ for the sequential loss of $\mathrm{B}$ from the $\left(\mathrm{S}_{4}+4 \mathrm{~B}\right)$ complex, at $\mathrm{pH} 7$ and temperatures ranging from 15 to $45^{\circ} \mathrm{C}$, were measured using ESI-MS. Two different approaches were used to analyze the ESI-MS data, one based on the initial rate of change in the relative abundance of the $\left(\mathrm{S}_{4}+4 \mathrm{~B}\right)$ species, the other based on nonlinear fitting of the time-dependent relative abundances of all free and B-bound $\mathrm{S}_{4}$ species. The Arrhenius parameters determined from the $k_{\text {off }}$ values measured by ESIMS were compared with the values obtained using the radiolabeled $B$ assay [14]. In addition to providing a quantitative measure of the dissociation rate constants, the direct ESI-MS measurements provide a definitive answer to the question of whether the sequential binding of $B$ to $S_{4}$ occurs in a cooperative or noncooperative fashion.

\section{Experimental}

\section{Streptavidin and Biotin}

The plasmid for natural core streptavidin (containing residues 13-139 of WT streptavidin, MW $13271 \mathrm{Da}$ ) was a gift from Professor P. Stayton (University of Washington). Streptavidin was expressed in $E$. coli and purified using procedures described elsewhere [42]. Solutions of purified $\mathrm{S}_{4}$ were exchanged directly into $100 \mathrm{mM}$ aqueous ammonium acetate buffer using an Amicon microconcentrator with a MW cut-off of $10 \mathrm{kDa}$ and lyophilized. Stock solutions of $\mathrm{S}_{4}(100 \mu \mathrm{M})$ were prepared by dissolving a known amount of lyophilized streptavidin into $100 \mathrm{mM}$ ammonium acetate and stored at $-20{ }^{\circ} \mathrm{C}$ until needed. Biotin (B, MW 244.3 Da) was purchased from Sigma-Aldrich Canada (Oakville, Canada). The stock solution of B $(800 \mu \mathrm{M})$ was prepared by dissolving B in Milli$\mathrm{Q}$ water. All stock solutions were stored at $-20^{\circ} \mathrm{C}$ until needed.

\section{Mass Spectrometry}

All measurements were performed using an Apex Qe 9.4 T Fourier-transform ion cyclotron resonance (FTICR) mass spectrometer (Bruker, Billerica, MA, USA). Nanoflow ESI (nanoESI) was performed using borosilicate tubes $(1.0 \mathrm{~mm}$ o.d., $0.68 \mathrm{~mm}$ i.d.), pulled to $\sim 5 \mu \mathrm{m}$ o.d. at one end using a P-97 micropipette puller (Sutter Instruments, Novato, CA, USA). The electric field required to spray the solution in positive ion mode was established by applying a voltage of $1.0-1.3 \mathrm{kV}$ to a platinum wire inserted inside the glass tip. The solution flow rate was typically $\sim 20 \mathrm{nLmin}^{-1}$. Details of the instrumental and experimental conditions typically used for quantifying proteinligand interactions can be found elsewhere [43].

\section{Kinetic Measurements}

For the kinetic measurements, the reaction mixtures were prepared by mixing aliquots of the stock solutions to achieve the desired concentrations of $\mathrm{S}_{4}(10 \mu \mathrm{M}), \mathrm{B}(10-$ $26 \mu \mathrm{M})$ and ammonium acetate $(5 \mathrm{mM})$. The reaction 
mixtures were kept at constant temperature $\left(15-45{ }^{\circ} \mathrm{C}\right)$ using a water bath (Colora, Germany). Aliquots of the reaction mixtures were removed at specific reaction times $(t)$ and analyzed by ESI-MS. Three ESI mass spectra were measured for each aliquot. An acquisition time of approximately $1 \mathrm{~min}$ was used for each mass spectrum.

\section{Data Analysis}

Assuming that the four ligand binding sites of $\mathrm{S}_{4}$ are kinetically equivalent and independent, vide infra, the apparent rate constants for ligand association and dissociation reactions $\left(k_{o n, i}\right.$ and $k_{o f f,(i+1)}$, respectively) for each $\left(\mathrm{S}_{4}+i \mathrm{~B}\right)$ species Equation (1) are related to the intrinsic (microscopic) rate constants $\left(k_{o n}\right.$ and $\left.k_{o f f}\right)$ through statistical factors, which reflect the number of free and occupied binding sites, Equations (2a) and (2b):

$$
\begin{aligned}
& k_{\text {on }, i} \\
& \left(\mathrm{~S}_{4}+i \mathrm{~B}\right)+\mathrm{B} \rightleftarrows\left(\mathrm{S}_{4}+(i+1) \mathrm{B}\right) \\
& k_{\text {off },(i+1)} \\
& k_{o n, i}=(4-i) k_{o n} \\
& k_{\text {off },(i+1)}=(i+1) k_{\text {off }}
\end{aligned}
$$

It follows that the rate of change of the concentration of each $\left(\mathrm{S}_{4}+i \mathrm{~B}\right)$ species can be described by Equations (3a)-(3e):

$$
\begin{gathered}
\frac{d\left(\left[\mathrm{~S}_{4}\right]\right)}{d t}=-4 k_{o n}[\mathrm{~B}]\left[\mathrm{S}_{4}\right]+k_{\text {off }}\left[\mathrm{S}_{4}+\mathrm{B}\right] \\
\frac{d\left(\left[\mathrm{~S}_{4}+\mathrm{B}\right]\right)}{d t}=-\left(3 k_{\text {on }}[\mathrm{B}]+k_{\text {off }}\right)\left[\mathrm{S}_{4}+\mathrm{B}\right]+4 k_{\text {on }}[\mathrm{B}]\left[\mathrm{S}_{4}\right]+ \\
2 k_{\text {off }}\left[\mathrm{S}_{4}+2 \mathrm{~B}\right] \\
+3 k_{\text {on }}[\mathrm{B}]\left[\mathrm{S}_{4}+\mathrm{B}\right]+3 k_{\text {off }}\left[\mathrm{S}_{4}+3 \mathrm{~B}\right] \\
\frac{d\left(\left[\mathrm{~S}_{4}+2 \mathrm{~B}\right]\right)}{d t}=-\left(2 k_{\text {on }}[\mathrm{B}]+2 k_{o f f}\right)\left[\mathrm{S}_{4}+2 \mathrm{~B}\right] \\
+2 k_{\text {on }}[\mathrm{B}]\left[\mathrm{S}_{4}+2 \mathrm{~B}\right] \\
+4 k_{o f f}\left[\mathrm{~S}_{4}+4 \mathrm{~B}\right] \\
\frac{d\left(\left[\mathrm{~S}_{4}+3 \mathrm{~B}\right]\right)}{d t}=-\left(k_{\text {on }}[\mathrm{B}]+3 k_{\text {off }}\right)\left[\mathrm{S}_{4}+3 \mathrm{~B}\right] \\
\frac{d\left(\left[\mathrm{~S}_{4}+4 \mathrm{~B}\right]\right)}{d t}=-4 k_{\text {off }}\left[\mathrm{S}_{4}+4 \mathrm{~B}\right]+k_{\text {on }}[\mathrm{B}]\left[\mathrm{S}_{4}+3 \mathrm{~B}\right]
\end{gathered}
$$

where $\left[\mathrm{S}_{4}+i \mathrm{~B}\right]$ is the concentration of the $\left(\mathrm{S}_{4}+i \mathrm{~B}\right)$ species and $[\mathrm{B}]$ is the concentration of free $\mathrm{B}$.

Because the rate of association of $\mathrm{B}$ to $\mathrm{S}_{4}$ is very high, [B] will be extremely small when substoichiometric amounts of ligand are used (which is the case in the present study). Consequently, it is reasonable to assume that $[\mathrm{B}]$ exists at a steady-state over the course of the entire reaction. Therefore, the $i k_{o n}[\mathrm{~B}]$ terms can be approximated as $i k_{1}$, where $k_{1}$ is a pseudo first-order rate constant. Equations (3a)-(3e) can then be rewritten in terms of the normalized abundances $\left(A_{R\left(\mathrm{~S}_{4}+i \mathrm{~B}\right)}\right)$ of the $\left(\mathrm{S}_{4}+i \mathrm{~B}\right)$ species, Equations (4a)-(4e):

$$
\begin{aligned}
\frac{d A_{R} \mathrm{~S}_{4}}{d t}= & -4 k_{1} A_{R \mathrm{~S}_{4}}+k_{\text {off }} A_{R\left(\mathrm{~S}_{4}+\mathrm{B}\right)} \\
\frac{d A_{R\left(\mathrm{~S}_{4}+\mathrm{B}\right)}}{d t}= & -\left(3 k_{1}+k_{o f f}\right) A_{R\left(\mathrm{~S}_{4}+\mathrm{B}\right)}+4 k_{1} A_{R \mathrm{~S}_{4}} \\
& +2 k_{\text {off }} A_{R\left(\mathrm{~S}_{4}+2 \mathrm{~B}\right)} \\
\frac{d A_{R\left(\mathrm{~S}_{4}+2 \mathrm{~B}\right)}^{d t}=}{d t} & -\left(2 k_{1}+2 k_{o f f}\right) A_{R\left(\mathrm{~S}_{4}+2 \mathrm{~B}\right)} \\
& +3 k_{1} A_{R\left(\mathrm{~S}_{4}+\mathrm{B}\right)}+3 k_{\text {off }} A_{R\left(\mathrm{~S}_{4}+3 \mathrm{~B}\right)} \\
\frac{d A_{R\left(\mathrm{~S}_{4}+3 \mathrm{~B}\right)}^{d t}=}{d t} & -\left(k_{1}+3 k_{o f f}\right) A_{R\left(\mathrm{~S}_{4}+3 \mathrm{~B}\right)} \\
& +2 k_{1} A_{R\left(\mathrm{~S}_{4}+2 \mathrm{~B}\right)}+4 k_{o f f} A_{R\left(\mathrm{~S}_{4}+4 \mathrm{~B}\right)}
\end{aligned}
$$

$$
\frac{d A_{R\left(\mathrm{~S}_{4}+4 \mathrm{~B}\right)}}{d t}=-4 k_{o f f} A_{R\left(\mathrm{~S}_{4}+4 \mathrm{~B}\right)}+k_{1} A_{R\left(\mathrm{~S}_{4}+3 \mathrm{~B}\right)}
$$

As described below, under the solution conditions used in the present study, there is a significant difference in the ligand association and dissociation rates immediately upon mixing $\mathrm{S}_{4}$ and $\mathrm{B}[9,13,14]$. Because of this and the fact that the initial concentration of $\mathrm{B}$ is less than the total concentration of binding sites, mixing $\mathrm{S}_{4}$ with $\mathrm{B}$ initially produces a non-equilibrium distribution of $\left(\mathrm{S}_{4}+i \mathrm{~B}\right)$, one that favors the $\mathrm{S}_{4}$ and $\left(\mathrm{S}_{4}+4 \mathrm{~B}\right)$ species. As the reaction proceeds, the relative abundance of $\left(\mathrm{S}_{4}+\right.$ 4B) will decrease and system will eventually achieve an equilibrium distribution of $\left(\mathrm{S}_{4}+i \mathrm{~B}\right)$ species. Because $A_{R\left(\mathrm{~S}_{4}+3 \mathrm{~B}\right)}$ is initially relatively small, the rate of change of $A_{R\left(\mathrm{~S}_{4}+4 \mathrm{~B}\right)}$, described by Equation (4e), can be approximated by Equation (5):

$$
\frac{d A_{R\left(\mathrm{~S}_{4}+4 \mathrm{~B}\right)}}{d t} \approx-4 k_{o f f} A_{R\left(\mathrm{~S}_{4}+4 \mathrm{~B}\right)}
$$


and $k_{\text {off }}$ can be evaluated from a linear least squares fit of the plot of the natural logarithm of $A_{R\left(\mathrm{~S}_{4}+4 \mathrm{~B}\right)}$ versus $t$, Equation (6):

$$
\ln A_{R\left(\mathrm{~S}_{4}+4 \mathrm{~B}\right)}=-4 k_{\text {off }} \times t+b
$$

where $b$ is a constant that is equal to $\ln A_{R\left(\mathrm{~S}_{4}+4 \mathrm{~B}\right)}$ at $t=0$. In this case, $t=0$ corresponds to the earliest reaction time for which ESI mass spectra were acquired. It should be noted that the magnitude of $b$ depends on the initial concentrations of $\mathrm{S}_{4}$ and $\mathrm{B}$.

An alternative approach to determining $k_{\text {off }}$ involves applying nonlinear regression analysis to the time-dependence of $A_{R\left(\mathrm{~S}_{4}+i \mathrm{~B}\right)}$ for each $\left(\mathrm{S}_{4}+i \mathrm{~B}\right)$ species. This approach is more general than the initial rate method described above since there are no simplifying assumptions needed and $k_{l}$, in addition to $k_{\text {off }}$, can be determined. Moreover, this approach is not limited to data measured early in the reaction. In fact, inclusion of data measured at longer times, where the system is approaching equilibrium, enhances the reliability of the fitting procedure. Expressions for the time-dependent $A_{R\left(\mathrm{~S}_{4}+i \mathrm{~B}\right)}$ for each $\left(\mathrm{S}_{4}+i \mathrm{~B}\right)$ species are obtained by solving Equations (4a)-(4e) (as a system) using Maple 14 (Maplesoft, Waterloo, Canada). The experimental $A_{R\left(\mathrm{~S}_{4}+i \mathrm{~B}\right)}$ values at $t=0$ (the earliest time point measured) served as a boundary conditions. Shown in Supplementary Data is a set of solutions (functions) corresponding to experimental data acquired at $44.8^{\circ} \mathrm{C}$. Origin (OriginLab, Northampton, MA, USA) was used to fit the functions (with $k_{\text {off }}$ and $k_{1}$ as adjustable parameters) to the experimental breakdown curves $\left(A_{R\left(\mathrm{~S}_{4}+i \mathrm{~B}\right)}\right.$ values plotted versus $t$ ). At each temperature, $k_{\text {off }}$ and $k_{1}$ values were calculated for each $\left(\mathrm{S}_{4}+i \mathrm{~B}\right)$ species; the reported $k_{\text {off }}$ and $k_{1}$ values in Table 1 correspond to the average of these values.

The temperature dependence of the measured $k_{\text {off }}$ values was analyzed according to the Arrhenius equation, Equation (7):

$$
\ln \left(k_{\text {off }}\right)=-\frac{\mathrm{E}_{\mathrm{a}}}{\mathrm{RT}}+\ln (\mathrm{A})
$$

The activation energy $\left(E_{a}\right)$ and pre-exponential factor $(A)$ were calculated from the slope and intercept, respectively, of a linear least-squares fit of the plot of $\ln \left(k_{\text {off }}\right)$ versus $1 / \mathrm{T}$.

\section{Results and Discussion}

Shown in Figure 1a-c are representative ESI mass spectra acquired in positive ion mode for a solution $\left(\mathrm{pH} 7\right.$ and $\left.22.1^{\circ} \mathrm{C}\right)$ of $\mathrm{S}_{4}(10 \mu \mathrm{M})$ and $\mathrm{B}(14 \mu \mathrm{M})$ and ammonium acetate $(5 \mathrm{mM})$ immediately after mixing (i.e., reaction time $\sim 0 \mathrm{~min}$ ), and after $112 \mathrm{~min}$ and $1602 \mathrm{~min}(1.1 \mathrm{~d})$. In each mass spectrum, signals corresponding to the protonated $\left(\mathrm{S}_{4}+i \mathrm{~B}\right)^{\mathrm{n}+}$ ions with $0 \leq i \leq 4$, at $n=12-16$, are evident. Initially, the $\mathrm{S}_{4}{ }^{\mathrm{n}+}$ and $\left(\mathrm{S}_{4}+4 \mathrm{~B}\right)^{\mathrm{n}+}$ ions represent the dominant species present (Figure 1a). The observation of predominantly free and fully ligand-bound protein shortly after mixing B with $\mathrm{S}_{4}$ is consistent with results of Sano and Cantor [44]. These authors used gel electrophoresis to analyze solutions of $\mathrm{B}$ and $\mathrm{S}_{4}$, immediately after mixing, and observed only two major bands, which corresponded to $S_{4}$ and $\left(S_{4}+4 B\right)$ [44]. The authors interpreted these results as evidence of cooperative ligand binding [44]. However, the observation of abundant $\mathrm{S}_{4}$ and $\left(\mathrm{S}_{4}+4 \mathrm{~B}\right)$ in the ESI mass spectra does not necessarily imply cooperative binding of $\mathrm{B}$ to $\mathrm{S}_{4}$. Instead, mixing of $\mathrm{S}_{4}$ and $\mathrm{B}$ could lead initially to a non-equilibrium distribution of streptavidin-biotin species due to the fast association kinetics and extremely slow dissociation kinetics. The latter explanation finds support in the observation that the distribution of $\left(\mathrm{S}_{4}+i \mathrm{~B}\right)$ species changes at longer reaction times. For example, after $112 \mathrm{~min}$, abundant signal is observed for all five of the $\left(\mathrm{S}_{4}+i \mathrm{~B}\right)$ species (i.e., with $i$ from 0 to 4) although $\mathrm{S}_{4}$ remains the dominant species detected (Figure 1b); after $1602 \mathrm{~min}$, the $\left(\mathrm{S}_{4}+\mathrm{B}\right)$ species dominates (Figure 1c). At much longer times, a constant distribution of $\left(\mathrm{S}_{4}+i \mathrm{~B}\right)$ species is observed, indicating that an equilibrium distribution of $\left(\mathrm{S}_{4}+i \mathrm{~B}\right)$ species was reached. As an example, shown in Figure 1d is a representative ESI mass spectrum acquired after $13080 \min (9$ d). Notably, the measured distribution of $\left(\mathrm{S}_{4}+i \mathrm{~B}\right)$ species agrees with the distribution expected in the case of four identical and independent ligand binding sites, each with a microscopic $K_{a}$ of $2.5 \times 10^{13} \mathrm{M}^{-1}$ (at pH 7.4 and $25^{\circ} \mathrm{C}$ ) (Figure 1e) [13]. These results establish, unambiguously, that $\mathrm{B}$ binding to $\mathrm{S}_{4}$ is not a cooperative process, in agreement with the findings of Jones and Kurzban [45] and Fidelio and co-workers [46], and that the binding sites are thermodynamically equivalent and independent. It is also concluded that the apparent cooperative distributions of the $\left(\mathrm{S}_{4}+i \mathrm{~B}\right)$ species observed at short reaction times are, in fact, of kinetic and not thermodynamic origin.

Table 1. Microscopic Rate Constants $\left(k_{\text {off }}\right)$ for the Dissociation of the Streptavidin-Biotin Interaction at $\mathrm{pH} 7$ and Temperatures Ranging from 15 to $45^{\circ} \mathrm{C}$ Measured Using Direct ESI-MS Analysis ${ }^{\text {a,b }}$

\begin{tabular}{lccccc}
\hline$\left[\mathrm{S}_{4}\right]_{\mathrm{o}}(\mu \mathrm{M})$ & {$[\mathrm{B}]_{\mathrm{o}}(\mu \mathrm{M})$} & $\mathrm{T}\left({ }^{\circ} \mathrm{C}\right)$ & $k_{\text {off }}\left(\mathrm{s}^{-1}\right)^{\mathrm{a}}$ Linear fitting & $k_{\text {off }}\left(\mathrm{s}^{-1}\right)^{\mathrm{b}}$ Nonlinear fitting & $k_{1}\left(\mathrm{~s}^{-1}\right)^{\mathrm{b}}$ Nonlinear fitting \\
\hline 10 & 20 & 15.3 & $(1.1 \pm 0.1) \times 10^{-6}$ & $(1.3 \pm 0.7) \times 10^{-6}$ & $(2.3 \pm 0.8) \times 10^{-6}$ \\
10 & 14 & 22.1 & $(4.1 \pm 0.1) \times 10^{-6}$ & $(5.5 \pm 0.3) \times 10^{-6}$ & $(2.8 \pm 0.9) \times 10^{-6}$ \\
10 & 10 & 30.5 & $(1.8 \pm 0.1) \times 10^{-5}$ & $(2.1 \pm 0.1) \times 10^{-5}$ & $(8.7 \pm 0.3) \times 10^{-6}$ \\
10 & 10 & 36.2 & $(5.0 \pm 0.2) \times 10^{-5}$ & $(5.1 \pm 0.1) \times 10^{-5}$ & $(1.8 \pm 0.3) \times 10^{-5}$ \\
10 & 10 & 44.8 & $(1.6 \pm 0.1) \times 10^{-4}$ & $(2.5 \pm 0.2) \times 10^{-4}$ & $(8.4 \pm 0.7) \times 10^{-5}$
\end{tabular}

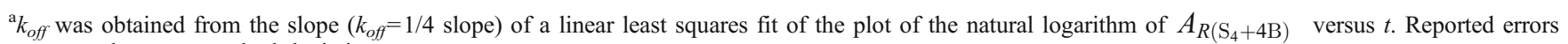
correspond to one standard deviation.

${ }^{\mathrm{b}}$ At each temperature, $k_{\text {off }}$ and $k_{1}$ were obtained from nonlinear regression analysis of the time-dependent relative abundance of each of the $\left(\mathrm{S}_{4}+i \mathrm{~B}\right)$ species. The reported $k_{\text {off }}$ and $k_{1}$ values correspond to the average of these values and errors are one standard deviation. 

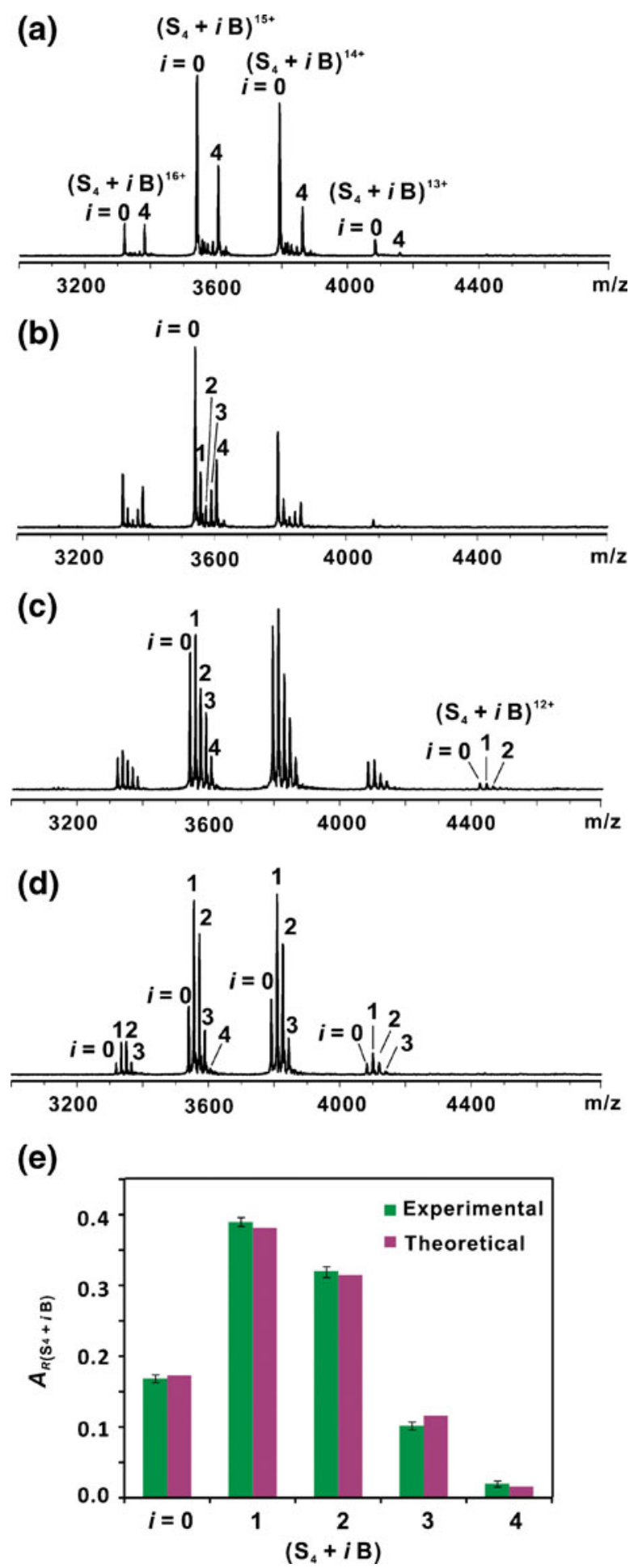

Figure 1. ESI mass spectra acquired for an aqueous ammonium acetate $(5 \mathrm{mM})$ solution of $\mathrm{S}_{4}(10 \mu \mathrm{M})$ and $\mathrm{B}(14 \mu \mathrm{M})$ at $22.1^{\circ} \mathrm{C}$ and $\mathrm{pH} 7$ and different reaction times (a) $0 \mathrm{~s}$, (b) $112 \mathrm{~min}$, (c) $1602 \mathrm{~min}$ (1.1 d), and (d) $13080 \mathrm{~min}$ (9 d). (e) Normalized distribution of $\left(\mathrm{S}_{4}+i \mathrm{~B}\right)$ species, where $i=0-4$, determined from the ESI mass spectrum shown in (d). The reported errors correspond to one standard deviation and were determined from three replicate measurements. Also shown is the calculated distribution for four equivalent ligand binding sites, each with a $K_{a}$ of $2.5 \times 10^{13} \mathrm{M}^{-1}$
As noted in the Data Analysis section, two different approaches were used to quantify $k_{\text {off }}$. One approach is based on the initial rate of change of $A_{R\left(\mathrm{~S}_{4}+i \mathrm{~B}\right)}$. Shown in Figure 2a are plots of the natural logarithm of $A_{R\left(\mathrm{~S}_{4}+i \mathrm{~B}\right)}$ versus $t$, measured at the reaction temperatures indicated. Importantly, the plots exhibit excellent linearity. This result indicates that neglect of the ligand association reaction involving $\left(\mathrm{S}_{4}+3 \mathrm{~B}\right)$ to $A_{R\left(\mathrm{~S}_{4}+4 \mathrm{~B}\right)}$ in Equation (4e) is a reasonable assumption. The $k_{\text {off }}$ values calculated at each reaction temperature are listed in Table 1. Notably, the value of $5.0 \times 10^{-5} \mathrm{~s}^{-1}$ determined at $36.2^{\circ} \mathrm{C}$ agrees very well with the reported value of $4.1 \times 10^{-5} \mathrm{~s}^{-1}$, which was measured at $37{ }^{\circ} \mathrm{C}$ [14]. An alternative approach used to determine $k_{\text {off }}$ involves
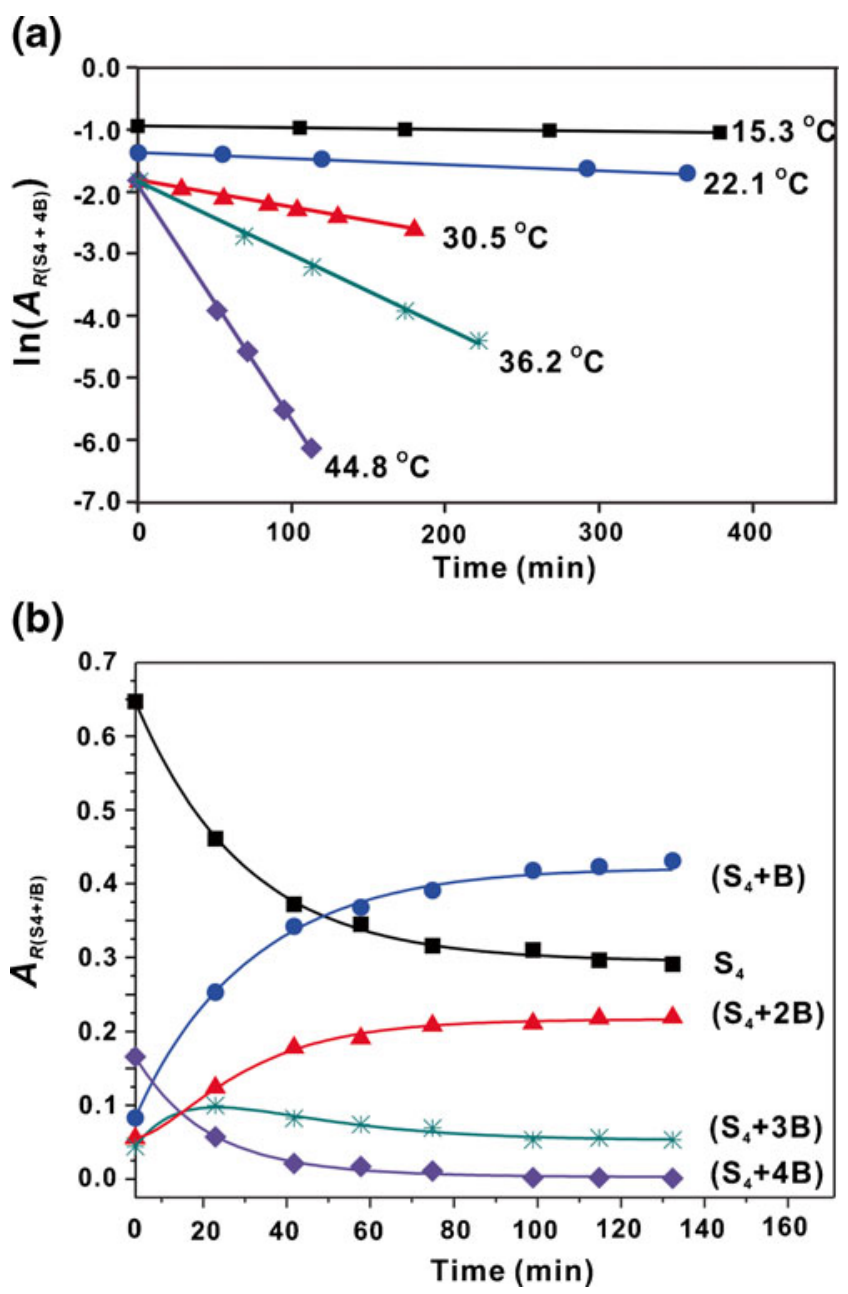

Figure 2. (a) Plots of the natural logarithm of $A_{R\left(\mathrm{~S}_{4}+i \mathrm{~B}\right)}$ versus reaction time measured by ESI-MS for neutral aqueous ammonium acetate $(5 \mathrm{mM})$ solutions of $\mathrm{S}_{4}(10 \mu \mathrm{M})$ and $B$ $(10-20 \mu \mathrm{M})$ at $15.3^{\circ} \mathrm{C}, 22.1^{\circ} \mathrm{C}, 30.5^{\circ} \mathrm{C}, 36.2^{\circ} \mathrm{C}$, and $44.8^{\circ} \mathrm{C}$. The solid curves represent linear least squares fits of the experimental data. (b) Plots of $A_{R\left(\mathrm{~S}_{4}+i \mathrm{~B}\right)}$ versus reaction time measured by ESI-MS neutral aqueous ammonium acetate $(5 \mathrm{mM})$ solution of $\mathrm{S}_{4}(10 \mu \mathrm{M})$, B $(10 \mu \mathrm{M})$ at $44.8^{\circ} \mathrm{C}$. The solid curves were determined from nonlinear regression analysis to the time-dependent $A_{R\left(\mathrm{~S}_{4}+i \mathrm{~B}\right)}$ values 
nonlinear fitting of the solutions of Equations (4a)-(4e) to the time-dependent $A_{R\left(\mathrm{~S}_{4}+i \mathrm{~B}\right)}$ values. Plotted in Figure $2 \mathrm{~b}$ are the $A_{R\left(\mathrm{~S}_{4}+i \mathrm{~B}\right)}$ values measured at $44.8{ }^{\circ} \mathrm{C}$ and the curves obtained from the nonlinear fitting procedure. It can be seen that the calculated curves describe the experimental data very well. The average kinetic parameters, determined at each temperature investigated, are summarized in Table 1 . Notably, the $k_{\text {off }}$ values determined by the two different methods agree very well, within a factor of 2 , at all of the temperatures investigated. For example, a $k_{\text {off }}$ value of $5.0 \times 10^{-5} \mathrm{~s}^{-1}$ was determined at $36.2^{\circ} \mathrm{C}$ with the nonlinear fitting method, which is indistinguishable from the value of $5.1 \times 10^{-5} \mathrm{~s}^{-1}$ determined from the initial rates approach. With the nonlinear fitting method, the $k_{I}\left(=k_{\text {on }}[\mathrm{B}]\right)$ terms were also established at each temperature investigated (Table 1). Although [B] is not accurately known (and, in fact, varies over the course of the reaction), it is nevertheless possible to estimate $k_{o n}$ by assuming that [B] (at all reaction times) is similar in magnitude to the $[\mathrm{B}]_{\mathrm{eq}}$, the concentration of free $\mathrm{B}$ at equilibrium. Following this approach, $k_{\text {on }}$ was estimated to be $1.3 \times 10^{8} \mathrm{M}^{-1} \mathrm{~s}^{-1}$ at $22.1{ }^{\circ} \mathrm{C}$ using a $[\mathrm{B}]_{\mathrm{eq}}$ of $2.2 \times 10^{-14} \mathrm{M}$, which was calculated for a solution of $\mathrm{S}_{4}(10 \mu \mathrm{M})$ and $\mathrm{B}$ $(14 \mu \mathrm{M})$ and a microscopic $K_{a}$ of $2.5 \times 10^{13} \mathrm{M}^{-1}$ [13]. This value of $k_{\text {on }}$ agrees reasonably well with a value of $4.5 \times$ $10^{7} \mathrm{M}^{-1} \mathrm{~s}^{-1}$, which was determined from measurements carried out at ambient temperature (not specified) using droplet microfluidics integrated with a confocal fluorescence detection system [9].

Shown in Figure 3 are the Arrhenius plots constructed from the $k_{\text {off }}$ values determined from the ESI-MS data using the two different data analysis approaches. The corresponding Arrhenius parameters $\left(\mathrm{E}_{\mathrm{a}}, \mathrm{A}\right)$ are listed in Table 2. Also shown in Figure 3 is the calculated curve based on the reported activation enthalpy and entropy, for the loss of $\mathrm{B}$ from the $\left(\mathrm{S}_{4}+4 \mathrm{~B}\right)$ complex in aqueous solution at $\mathrm{pH} 7.4$ [14]. Inspection of Figure 3 (and Table 2) reveals that the Arrhenius plots for the loss of $\mathrm{B}$ from the $\left(\mathrm{S}_{4}+4 \mathrm{~B}\right)$

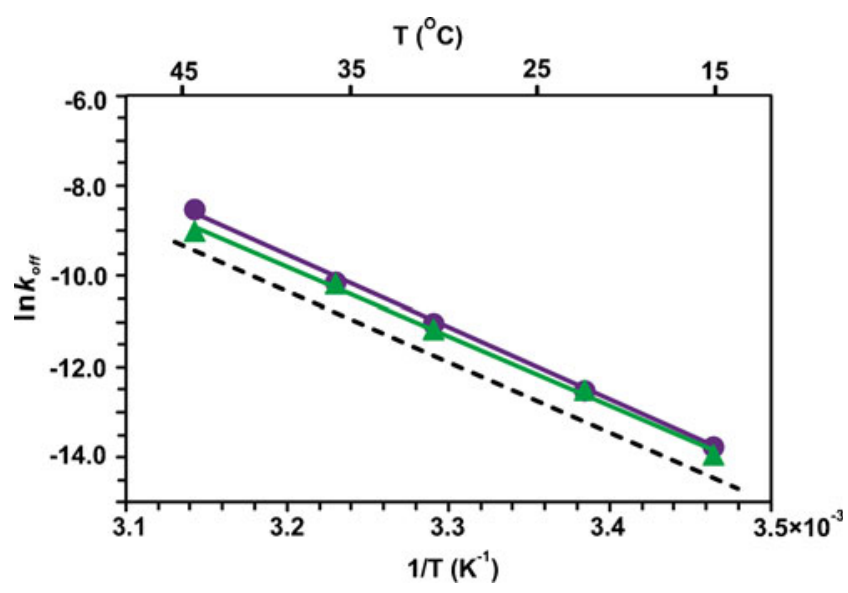

Figure 3. Arrhenius plots the loss of $B$ from the $\left(S_{4}+4 B\right)$ complex at $\mathrm{pH} 7$ constructed from $k_{\text {off }}$ values measured by ESI-MS [linear fitting $(\triangle)$, nonlinear fitting (O)] and corresponding plot (---) calculated from the activation enthalpy and entropy reported in [14]
Table 2. Arrhenius Activation Parameters $\left(E_{a}, A\right)$ for the Loss of $B$ from the $\left(\mathrm{S}_{4}+4 \mathrm{~B}\right)$ Complex Determined from $k_{\text {off }}$ Values Measured by ESI-MS (Using Linear and Nonlinear Data Analysis Methods) at $\mathrm{pH} \mathrm{7,} \mathrm{and}$ Arrhenius Parameters Measured at pH 7.4 Using a Radiolabeled Biotin Assay

\begin{tabular}{lcc}
\hline & $\mathrm{E}_{\mathrm{a}}\left(\mathrm{kcalmol}^{-1}\right)$ & $\mathrm{A}\left(\mathrm{s}^{-1}\right)$ \\
\hline ESI-MS (linear fitting) & $30.4 \pm 0.7^{\mathrm{a}}$ & $10^{17.1 \pm 0.5 \mathrm{a}}$ \\
ESI-MS (nonlinear fitting) & $31.7 \pm 0.8^{\mathrm{a}}$ & $10^{18.2 \pm 0.6 \mathrm{a}}$ \\
Radiolabeled biotin assay & $31.0 \pm 0.2^{\mathrm{b}}$ & $10^{17.3 \pm 0.1 \mathrm{~b}}$
\end{tabular}

${ }^{a}$ Reported errors correspond to one standard deviation.

${ }^{\mathrm{b}}$ Values calculated from the activation enthalpy and entropy reported in [14].

complex from linear and nonlinear fitting are similar, with $\mathrm{E}_{\mathrm{a}}$ values of $30.4 \pm 0.7$ and $31.7 \pm 0.8 \mathrm{kcalmol}^{-1}$, respectively. Moreover, the $\mathrm{E}_{\mathrm{a}}$ values agree with the reported value of $31.0 \pm 0.2 \mathrm{kcalmol}^{-1}[14]$. These findings indicate that both approaches to the analysis of the time-resolved ESI-MS data can provide a reliable determination of the temperaturedependence of $k_{o f f}$. However, the nonlinear fitting approach is more general and, in principle, can be applied in cases where sequential ligand binding exhibits cooperativity or where multiple, nonequivalent binding sites are present.

The streptavidin-biotin interaction is unusually kinetically stable and it takes several days to achieve an equilibrium distribution of $\left(\mathrm{S}_{4}+i \mathrm{~B}\right)$ species at the temperatures investigated. However, it is important to note that this same experimental approach could be applied, in an on-line fashion, to determine $k_{\text {off }}$ and, in principle, $k_{\text {on }}$ for proteinligand interactions that require less time to reach an equilibrium distribution. Given that $\sim 1 \mathrm{~min}$ is typically required to acquire an ESI mass spectrum (with a high signal-to-noise ratio) for solutions of protein-ligand complexes [47], it should be possible to apply this approach to complexes that take $>10$ min (under the desired solution conditions) to reach equilibrium. Although this approach will not be suitable for all protein-ligand complexes (those that exhibit both fast association and dissociation kinetics), the kinetic parameters for many protein-ligand interactions are expected to be accessible with this technique $[48,49]$.

\section{Conclusion}

In summary, ESI-MS measurements have been used to quantify $k_{\text {off }}$ for the sequential loss of B from the $\left(\mathrm{S}_{4}+4 \mathrm{~B}\right)$ complex at $\mathrm{pH} 7$ and temperatures ranging from $15{ }^{\circ} \mathrm{C}$ to $45^{\circ} \mathrm{C}$. Two different general strategies for data analysis were considered, one based on the initial rate of dissociation of the $\left(\mathrm{S}_{4}+4 \mathrm{~B}\right)$ complex, and the other employing nonlinear fitting of the timedependent $A_{R\left(\mathrm{~S}_{4}+i \mathrm{~B}\right)}$ values of the $\left(\mathrm{S}_{4}+i \mathrm{~B}\right)$ species. The two methods were found to yield $k_{\text {off }}$ values that agree within a factor of two. Importantly, the dissociation $E_{a}$ values measured by ESI-MS agree within $1 \mathrm{kcalmol}^{-1}$ with the reported value, which was measured using a radiolabeled $\mathrm{B}$ assay. In addition to providing a quantitative measure of $k_{\text {off }}$ at the temperatures investigated, the ESI-MS 
measurements also revealed, unambiguously, that sequential $\mathrm{B}$ binding to $\mathrm{S}_{4}$ occurs in a non-cooperative fashion and that the four ligand binding sites are kinetically and thermodynamically equivalent and independent.

\section{Acknowledgment}

The authors are grateful for financial support provided by the Natural Sciences and Engineering Research Council of Canada and the Alberta Glycomics Centre. The authors acknowledge Professor P. Stayton (University of Washington) for generously providing the streptavidin plasmid.

\section{References}

1. Copeland, R.A., Pompliano, D.L., Meek, T.D.: Drug-target residence time and its implications for lead optimization. Nat. Rev. Drug Discov. 5, 730-739 (2006)

2. Swinney, D.C.: The role of binding kinetics in therapeutically useful drug action. Curr. Opin. Drug Discovery Dev. 12, 31-39 (2009)

3. Callender, R., Dyer, R.B.: Advances in time-resolved approaches to characterize the dynamical nature of enzymatic catalysis. Chem. Rev. 106, 3031-3042 (2006)

4. Daghestani, H.N., Day, B.W.: Theory and applications of surface plasmon resonance, resonant mirror, resonant waveguide grating, and dual polarization interferometry biosensors. Sensors 10, 9630-9646 (2010)

5. De Crescenzo, G., Boucher, C., Durocher, Y., Jolicoeur, M.: Kinetic characterization by surface plasmon resonance-based biosensors: principle and emerging trends. Cell. Mol. Bioeng. 1, 204-215 (2008)

6. Bizzarri, A.R., Cannistraro, S.: Atomic force spectroscopy in biological complex formation: strategies and perspectives. J. Phy. Chem. B 113, 16449-16464 (2009)

7. Hill, J.J., Royer, C.A.: Fluorescence approaches to study of proteinnucleic acid complexation. Methods Enzymol. 278, 390-416 (1997)

8. Málnási-Csizmadia, A., Pearson, D.S., Kovács, M., Woolley, R.J., Geeves, M.A., Bagshaw, C.R.: Kinetic resolution of a conformational transition and the atp hydrolysis step using relaxation methods with a dictyostelium myosin ii mutant containing a single tryptophan residue. Biochemistry 40, 12727-12737 (2001)

9. Srisa-Art, M., Dyson, E.C., deMello, A.J., Edel, J.B.: Monitoring of real-time streptavidin-biotin binding kinetics using droplet microfluidics. Anal. Chem. 80, 7063-7067 (2008)

10. Sugawara, T., Kuwajima, K., Sugai, S.: Folding of staphylococcal nuclease A studied by equilibrium and kinetic circular dichroism spectra. Biochemistry 30, 2698-2706 (1991)

11. Chu, Y.H., Cheng, C.C.: Affinity capillary electrophoresis in biomolecular recognition. Cell. Mol. Life Sci. 54, 663-683 (1998)

12. Hall, D.R., Winzor, D.J.: Potential of biosensor technology for the characterization of interactions by quantitative affinity chromatography. J. Chromatogr. B 715, 163-181 (1998)

13. Chilkoti, A., Stayton, P.S.: Molecular origins of the slow streptavidinbiotin dissociation kinetics. J. Am. Chem. Soc. 117, 10622-10628 (1995)

14. Klumb, L.A., Chu, V., Stayton, P.S.: Energetic roles of hydrogen bonds at the ureido oxygen binding pocket in the streptavidin-biotin complex. Biochemistry 37, 7657-7663 (1998)

15. Gizachew, D., Dratz, E.: Transferred NOESY NMR studies of biotin mimetic peptide (fshpqnt) bound to streptavidin: a structural model for studies of peptide-protein interactions. Chem. Biol. Drug Des. 78, 14 $24(2011)$

16. Bao, J., Krylova, S.M., Wilson, D.J., Reinstein, O., Johnson, P.E., Krylov, S.N.: Kinetic capillary electrophoresis with mass-spectrometry detection (KCE-MS) facilitates label-free solution-based kinetic analysis of protein-small molecule binding. Chem, BioChem 12, 2551-2554 (2011)
17. Konermann, L., Collings, B.A., Douglas, D.J.: Cytochrome $c$ folding kinetics studied by time-resolved electrospray ionization mass spectrometry. Biochemistry 36, 5554-5559 (1997)

18. Lee, V.W.S., Chen, Y.-L., Konermann, L.: Reconstitution of aciddenatured holomyoglobin studied by time-resolved electrospray ionization mass spectrometry. Anal. Chem. 71, 4154-4159 (1999)

19. Sobott, F., Benesch, J.L.P., Vierling, E., Robinson, C.V.: Subunit exchange of multimeric protein complexes. Real-time monitoring of subunit exchange between small heat shock proteins by using electrospray mass spectrometry. J. Biol. Chem. 277, 38921-38929 (2002)

20. Simmons, D.A., Wilson, D.J., Lajoie, G.A., Doherty-Kirby, A., Konermann, L.: Subunit disassembly and unfolding kinetics of hemoglobin studied by time-resolved electrospray mass spectrometry. Biochemistry 43, 14792-14801 (2004)

21. Deng, G., Sanyal, G.: Applications of mass spectrometry in early stages of target based drug discovery. J. Pharm. Biomed. Anal. 40, 528-538 (2006)

22. Pan, J., Rintala-Dempsey, A.C., Li, Y., Shaw, G.S., Konermann, L.: Folding kinetics of the S100A11 protein dimer studied by time-resolved electrospray mass spectrometry and pulsed hydrogen-deuterium exchange. Biochemistry 45, 3005-3013 (2006)

23. Sharon, M., Robinson, C.V.: The role of mass spectrometry in structure elucidation of dynamic protein complexes. Annu. Rev. Biochem. 76, 167-193 (2007)

24. Clarke, D.J., Stokes, A.A., Langridge-Smith, P., Mackay, C.L.: Online quench-flow electrospray ionization fourier transform ion cyclotron resonance mass spectrometry for elucidating kinetic and chemical enzymatic reaction mechanisms. Anal. Chem. 82, 1897-1904 (2010)

25. Robbins, M.D., Yoon, O.K., Barbula, G.K., Zare, R.N.: Stopped-flow kinetic analysis using hadamard transform time-of-flight mass spectrometry. Anal. Chem. 82, 8650-8657 (2010)

26. Miao, Z., Chen, H., Liu, P., Liu, Y.: Development of submillisecond time-resolved mass spectrometry using desorption electrospray ionization. Anal. Chem. 83, 3994-3997 (2011)

27. Pacholarz, K.J., Garlish, R.A., Taylor, R.J., Barran, P.E.: Mass spectrometry based tools to investigate protein-ligand interactions for drug discovery. Chem. Soc. Rev. 41, 4335-4355 (2012)

28. Goodlett, D.R., Ogorzalek Loo, R.R., Loo, J.A., Wahl, J.H., Udseth, H.R., Smith, R.D.: A study of the thermal denaturation of ribonuclease $\mathrm{S}$ by electrospray ionization mass spectrometry. J. Am. Soc. Mass Spectrom. 5, 614-622 (1994)

29. Soya, N., Fang, Y., Palcic, M.M., Klassen, J.S.: Trapping and characterization of covalent intermediates of mutant retaining glycosyltransferases. Glycobiology 21, 547-552 (2011)

30. Deroo, S., Hyung, S.-J., Marcoux, J., Gordiyenko, Y., Koripella, R.K., Sanyal, S., Robinson, C.V.: Mechanism and Rates of exchange of L7/ L12 between ribosomes and the effects of binding EF-G. ACS Chem. Biol. 7, 1120-1127 (2012)

31. Peleg-Shulman, T., Najajreh, Y., Gibson, D.: Interactions of cisplatin and transplatin with proteins: Comparison of binding kinetics, binding sites and reactivity of the Pt-protein adducts of cisplatin and transplatin towards biological nucleophiles. J. Inorg. Biochem. 91, 306-311 (2002)

32. Pan, J., Konermann, L.: Calcium-induced structural transitions of the calmodulin-melittin system studied by electrospray mass spectrometry: conformational subpopulations and metal-unsaturated intermediates. Biochemistry 49, 3477-3486 (2010)

33. Rosu, F., Gabelica, V., Shin-ya, K., De Pauw, E.: Telomestatin-induced stabilization of the human telomeric DNA quadruplex monitored by electrospray mass spectrometry. Chem. Commun. 2702-2703 (2003)

34. Gabelica, V., Rosu, F., De Pauw, E.: A simple method to determine electrospray response factors of noncovalent complexes. Anal. Chem. 81, 6708-6715 (2009)

35. Chaiet, L., Wolf, F.J.: The properties of streptavidin, a biotin-binding protein produced by Streptomycetes. Arch. Biochem. Biophys. 106, 1-5 (1964)

36. Hendrickson, W.A., Pähler, A., Smith, J.L., Satow, Y., Merritt, E.A., Phizackerley, R.P.: Crystal structure of core streptavidin determined from multiwavelength anomalous diffraction of synchrotron radiation. Proc. Natl. Acad. Sci. U. S. A. 86, 2190-2194 (1989)

37. Chu, V., Stayton, P.S., Freitag, S., Le Trong, I., Stenkamp, R.E.: Thermodynamic and structural consequences of flexible loop deletion by circular permutation in the streptavidin-biotin system. Protein Sci. 7, 848-859 (1998)

38. Stayton, P.S., Freitag, S., Klumb, L.A., Chilkoti, A., Chu, V., Penzotti, J.E., To, R., Hyre, D., Le Trong, I., Lybrand, T.P., 
Stenkamp, R.E.: Streptavidin-biotin binding energetics. Biomol. Eng. 16, 39-44 (1999)

39. Li, Q., Gusarov, S., Evoy, S., Kovalenko, A.: Electronic structure, binding energy, and solvation structure of the streptavidin-biotin supramolecular complex: ONIOM and 3D-RISM study. J. Phy. Chem. B 113, 9958-9967 (2009)

40. Deng, L., Broom, A., Kitova, E.N., Richards, M.R., Zheng, R.B., Shoemaker, G.K., Meiering, E.M., Klassen, J.S.: Kinetic stability of the streptavidin-biotin interaction enhanced in the gas phase. J. Am. Chem. Soc. 134, 16586-16596 (2012)

41. Piran, U., Riordan, W.J.: Dissociation rate constant of the biotinstreptavidin complex. J. Immunol. Methods 133, 141-143 (1990)

42. Chilkoti, A., Tan, P.H., Stayton, P.S.: Site-directed mutagenesis studies of the high-affinity streptavidin-biotin complex: contributions of tryptophan residues 79, 108, and 120. Proc. Natl. Acad. Sci. 92, 1754-1758 (1995)

43. El-Hawiet, A., Kitova, E.N., Kitov, P.I., Eugenio, L., Ng, K.K., Mulvey, G.L., Dingle, T.C., Szpacenko, A., Armstrong, G.D., Klassen, J.S.: Binding of clostridium difficile toxins to human milk oligosaccharides. Glycobiology 21, 1217-1227 (2011)
44. Sano, T., Cantor, C.R.: Cooperative biotin binding by streptavidin. Electrophoretic behavior and subunit association of streptavidin in the presence of $6 \mathrm{M}$ urea. J. Biol. Chem. 265, 3369-3373 (1990)

45. Jones, M.L., Kurzban, G.P.: Noncooperativity of biotin binding to tetrameric streptavidin. Biochemistry 34, 11750-11756 (1995)

46. Gonzalez, M., Bagatolli, L., Echabe, I., Arrondo, J., Argarana, C., Cantor, C., Fidelio, G.: Interaction of biotin with streptavidinthermostability and conformational changes upon binding. J. Biol. Chem. 272, 11288-11294 (1997)

47. Kitova, E., El-Hawiet, A., Schnier, P., Klassen, J.: Reliable determinations of protein-ligand interactions by direct ESI-MS measurements. Are we there yet? J. Am. Soc. Mass Spectrom 23, 431-441 (2012)

48. Nunez, S., Venhorst, J., Kruse, C.G.: Target-drug interactions: first principles and their application to drug discovery. Drug Discov. Today 17, 10-22 (2012)

49. Tummino, P.J., Copeland, R.A.: Residence time of receptor-ligand complexes and its effect on biological function. Biochemistry 47, 54815492 (2008) 